\title{
Growth Cones in Developing Cultured Cortical Neurons
}

\author{
Hiroaki Asou*, Noriko Mutou and Shusuke Hirano \\ Department of Physiology, Toho University School of Medicine, Ohmorinishi \\ Tokyo 143, Japan
}

\begin{abstract}
Large numbers of growth cones were present in 6-day-old primary cultures of cerebral hemispheres from fetal rats. The average size of the growth cones was 24 by $28 \mu \mathrm{m}$. Many of these growth cones had both veillike lamellipodia and filopodia. A few cones remained in 21-day-old cultures. These also had lamellipodia and filopodia. Ganglioside $\mathrm{GM}_{1}$ was present in both 6-day-old and 21-day-old cultured growth cones.
\end{abstract}

Growth cones at the terminals of outgrowing neurites are responsible for the formation of correct neuronal connections during development because they are the part of the neuron that recognizes its specific target cell. The structure of the growth cone and its function in vivo $(10,25,26)$ and in vitro $(1,8,15,18,20)$ recently has received much study. A major obstacle in doing such studies is the difficulty in obtaining pure nerve cell cultures after seeding. Non-neuronal cells, especially astrocytes, readily proliferate during culture and appear as the major contaminant within a short period. We largely overcame this problem by using an astrocyte-deficient culture in which neurons are allowed to grow but glial cell growth is limited by the culture conditions. This was accomplished by inhibiting glial cell growth by the complement-dependent, antibody-mediated destruction of glial cells (6).

We are interested in determining the mechanism by which an outgrowing growth cone selects the appropriate pathway to its target cell. Cell surface molecules are assumed to behave as an antigen-antibody system by which a neuron-neuron connection is established. One candidate for the active cell membrane constituent that functions in the formation of correct connections is the gangliosides (17). Gangliosides are abundant in neural tissue and may act as receptors for circulating ligands or in intercellular interactions (14). Therefore, the cell surface membrane and gangliosides may indeed be intimately related. We here report on our investigation of whether ganglioside $\mathrm{GM}_{1}$ is localized in the growth cones of outgrowing neurites.

\section{MATERIALS AND METHODS}

The technique used to produce astrocyte-deficient cultures from the embryonic rat cerebral cortex has been described elsewhere (6). Briefly, cerebral hemispheres were dissected from the

* Present address: Institut für Neurobiologie der Universität Heidelberg Im Neuenheimer Feld 364 D-6900 Heidelberg Fed. Rep. Germany

Abbreviations used: MEM, Eagle's minimum essential medium; SFCS, semi-fetal calf serum; SEM, scanning electron microscopy; ABC, avidin-biotin complex; NF, neurofilament; PBS, phosphate-buffered saline; BSA, bovine serum albumin. 
brains of 17-day-old fetal rats then dissociated by extrusion through a stainless steel mesh (140 $\mu \mathrm{m}$ opening size, 100 mesh screen) into a culture dish that held Eagle's minimum essential medium (MEM) containing 15\% semi-fetal calf serum (SFCS) (Mitsubishi Chemical Industries Ltd. Tokyo); $0.6 \%$ glucose; $0.05 \% \mathrm{NaHCO}_{3} ; 292 \mathrm{mg} / \mathrm{l}$ of L-glutamine; $100 \mu \mathrm{g} / \mathrm{ml}$ of kanamycin; anti-GFAP antiserum obtained from DAKO, CA. USA, diluted $1: 1000$ in MEM; and lyophilized guinea pig serum obtained from Nippon Biosupply Center, Tokyo, diluted 1:700 in MEM, titer $1: 71.4$ for the complement-dependent, antiglial antibody-mediated cytotoxic cultures.

After a $30 \mathrm{~min}$ incubation with shaking, the cells were separated from the medium by centrifugation at $500 \times \mathrm{g}$ for $7 \mathrm{~min}$. The experimental medium then was replaced with fresh MEM without antibody and complement. Cell density was $10^{4}$ visible cells per $73 \times 15 \mathrm{~mm}$ glass Leighton tube (Matsunami glass Inc. Tokyo) topped with a poly-L-lysine-coated microcoverglass $(12 \times 32 \mathrm{~mm})$. The medium was replaced after the first day and renewed every fourth day during culture for 21 days in $3 \% \mathrm{CO}_{2}$ and $97 \%$ air at $37^{\circ} \mathrm{C}$. The biotinylated choleragen that was used to identify ganglioside $\mathrm{GM}_{1}$ was prepared as described elsewhere $(4,5)$. Briefly, cultured cells were fixed with a $4 \%$ solution of paraformaldehyde then treated at $4{ }^{\circ} \mathrm{C}$ overnight with biotinylated choleragen at $5 \mu \mathrm{g} / \mathrm{ml}$ in PBS. After several washings with PBS containing BSA $(2 \mathrm{mg} / \mathrm{ml})$, the cells were treated for $30 \mathrm{~min}$ at $37^{\circ} \mathrm{C}$ with avidinperoxidase at $5 \mu \mathrm{g} / \mathrm{ml}$ in PBS.

A fluorescence microscopic study was done to identify neurons (5), with anti-neurofilament antibody as the cell marker (3). Immunocytochemical staining was done to analyze the growth cone. The method of Sternberger (23) was used to measure the growth cone dimensions, the intersection of the long axis of the axon with the leading margin of the growth cone being measured according to the method of Bray and Chapman (8) (see Fig. 2b).

Scanning electron microscopy (SEM) was used after rinsing the cell cultures on the coverslips with PBS and slowly infusing them for $120 \mathrm{~min}$ at room temperature with a fixative containing $1 \%$ glutaraldehyde in $0.15 \mathrm{M}$ PBS, then rinsing them with PBS and dehydrating the preparation sequentially with $50,70,80,90$ and $100 \%$ ethanol.

After dehydration, the coverslips were critical point dried (Sorvall Apparatus) then coated with Au-Pd in a Sputter Coater and viewed with an S-450 Hitachi (Japan) scanning electron microscope (2).

\section{RESULTS}

Neurons from 3-day-old astrocyte-deficient cultures were identified by immunofluorescent staining with the avidin-biotin complex (ABC). Neurons and a lesser number of oligodendrocytes were the major cell components. The percentage of GFAP-positive cells had been reduced to a range of $2-8 \%$ in these cultures. Biotinylated anti-neurofilament antiserum was used to identify neurons (Fig. 1). Table 1 gives the average dimensions of 56 growth cones in 6-day-old cultures of cortical neurons. Types 2 and 3 accounted for $65 \%$ of the total growth cones. Equal numbers of types 1 and 4 were present. Immunoperoxidase staining of 6-day-old cultures from rat embryonic cerebral cortex (Fig. 2) for ganglioside $\mathrm{GM}_{1}$ with biotinylated choleragen showed that ganglioside $\mathrm{GM}_{1}$ may be localized in the growth cone. Cones also were stained positively with anti-ganglioside $\mathrm{GM}_{1}$ antibody (data not shown) (6). Many neurons bearing various veil-like lamellipodia and prominant filopodia were present. Although there are many variations in form, type 1 growth cones are larger, more articulated and have a variety of lamellipodia (some with long 


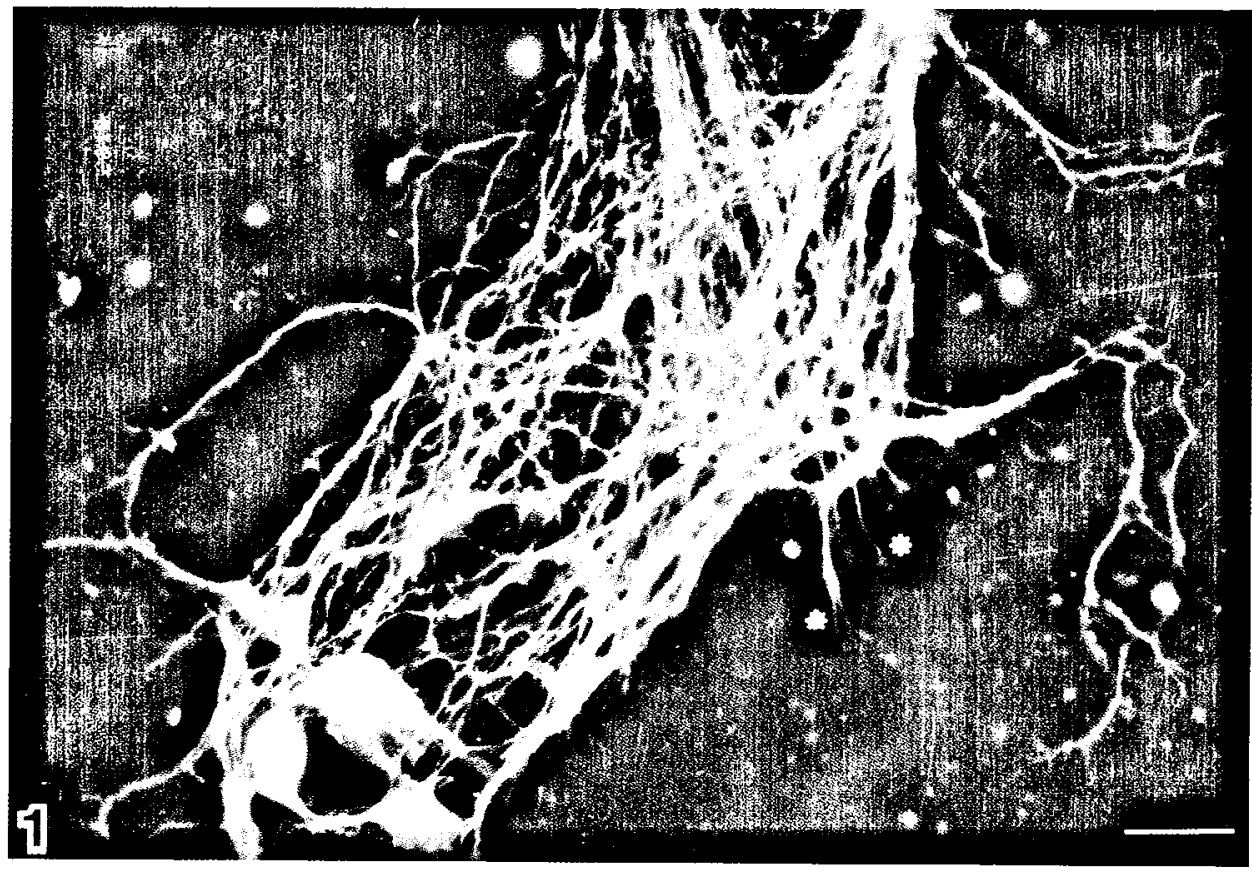

Fig. 1. Immunofluorescence staining for NF protein in 3-day-old primary cultures. Neurites and growth cones of neurons stained with anti-NF antibody (asterisk). Bar $=20 \mu \mathrm{m}$

microtips of filopodia) than do types 2,3 and 4 .

Immunoperoxidase staining for ganglioside $\mathrm{GM}_{1}$ in 21 -day-old cultured cells (Fig. 3) showed that ganglioside $\mathrm{GM}_{1}$ is localized in the growth cones. Neuritic processes or cortical neurons clearly were present in these long term cultures (Fig. 3a, arrow). The number of growth cones in 21-day-old neurons were few, but they still had a very few veil-like structures. Various short filopodia-like structures could still be seen in these cultures. The surprising finding was that a form of the type 2 growth cone and its phenomena (veil-like lamellipodia and filopodia-like structures) survived for 3 weeks (Fig. 3b, large arrow).

TABLE 1. ChARACTERISTICS OF GROWTH CONES IN PRIMARY CULTURES OF EMBRYONIC RAT CEREBRAL CORTEX

\begin{tabular}{lrrrr}
\hline & \multicolumn{4}{c}{ Type of Growth Cone $(\mu \mathrm{m})$} \\
\cline { 2 - 5 } Measurements & \multicolumn{1}{c}{ Type 1 } & Type 2 & Type 3 & Type 4 \\
\hline Overall Width (Wf) & $35.5 \pm 4.1$ & $23.7 \pm 2.8$ & $13.9 \pm 2.6$ & $6.2 \pm 1.2$ \\
Base Width (Wi) & $12.6 \pm 1.2$ & $9.6 \pm 2.4$ & $6.2 \pm 1.4$ & $2.3 \pm 0.8$ \\
Overall Length (Lf) & $36.1 \pm 5.5$ & $28.1 \pm 7.5$ & $22.2 \pm 5.5$ & $14.4 \pm 3.9$ \\
Base Length (Li) & $23.6 \pm 6.2$ & $18.6 \pm 8.3$ & $13.3 \pm 2.4$ & $8.0 \pm 3.3$ \\
Proportion of Growth Cone (\%) & $17.9 \pm 4.8$ & $42.9 \pm 5.9$ & $21.4 \pm 3.4$ & $17.8 \pm 2.3$ \\
\hline
\end{tabular}

The culture was 6 days old at the time of measurement. Data given are the Means \pm SD for the 56 growth cones measured. 


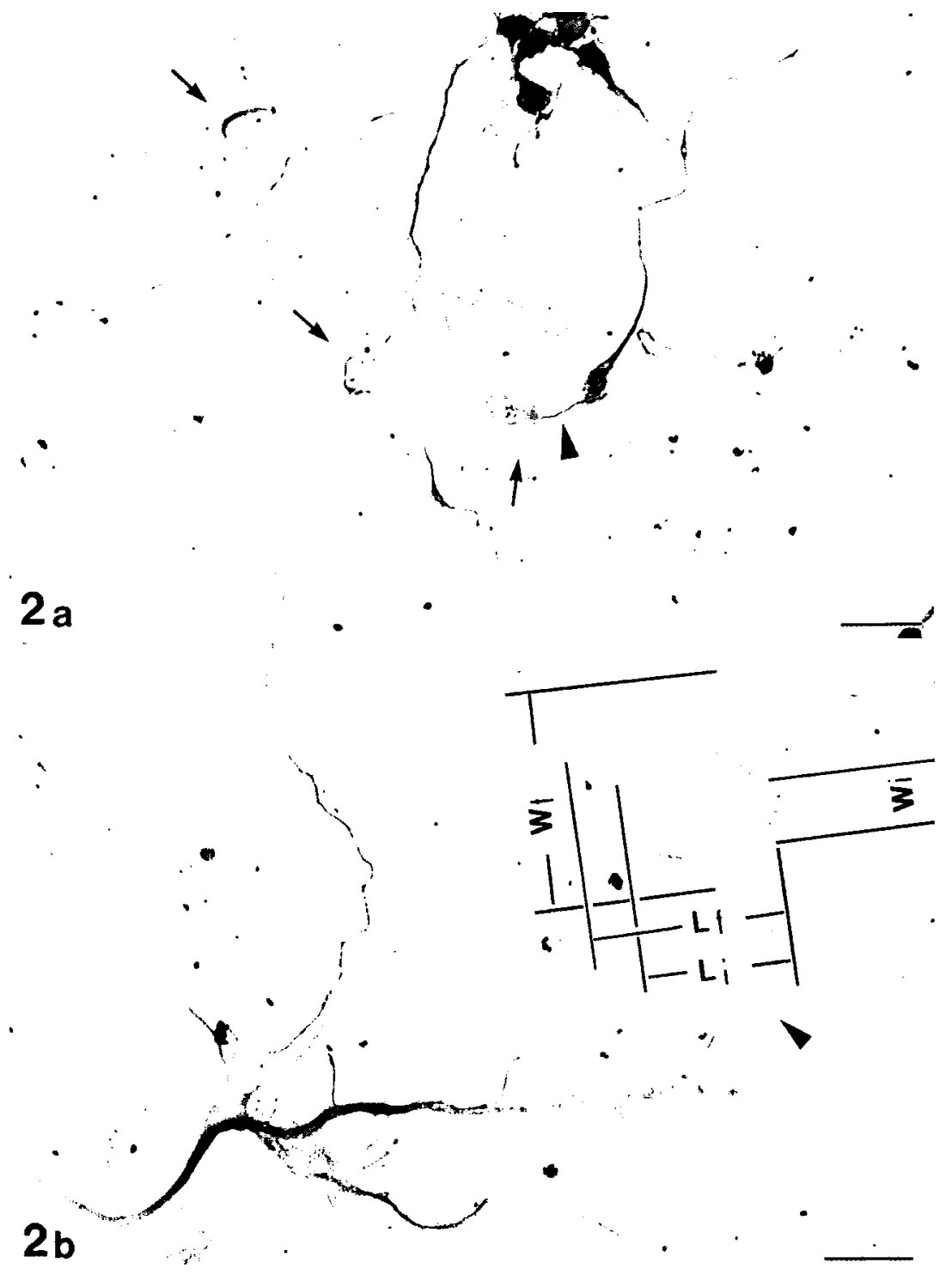

Fig. 2. Immunoperoxidase staining for ganglioside $\mathrm{GM}_{1}$ with the avidin-biotin complex system

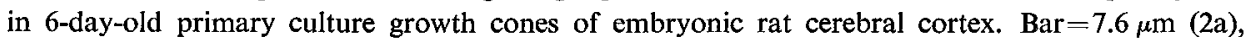
$B a r=15 \mu \mathrm{m}(2 \mathrm{~b})$. Various veil-like lamellipodia bearing numerous filopodia were stained with ganglioside $\mathrm{GM}_{1}$ (2a, arrows). One of the microtips of the filopodia of the cone extends to the target neurite (Fig. 2a, b, arrowhead). The dimensions given are for overall length (Lf), base length (Li), overall width (Wf) and base width (Wi) as described by Bray and Chapman (1985). 


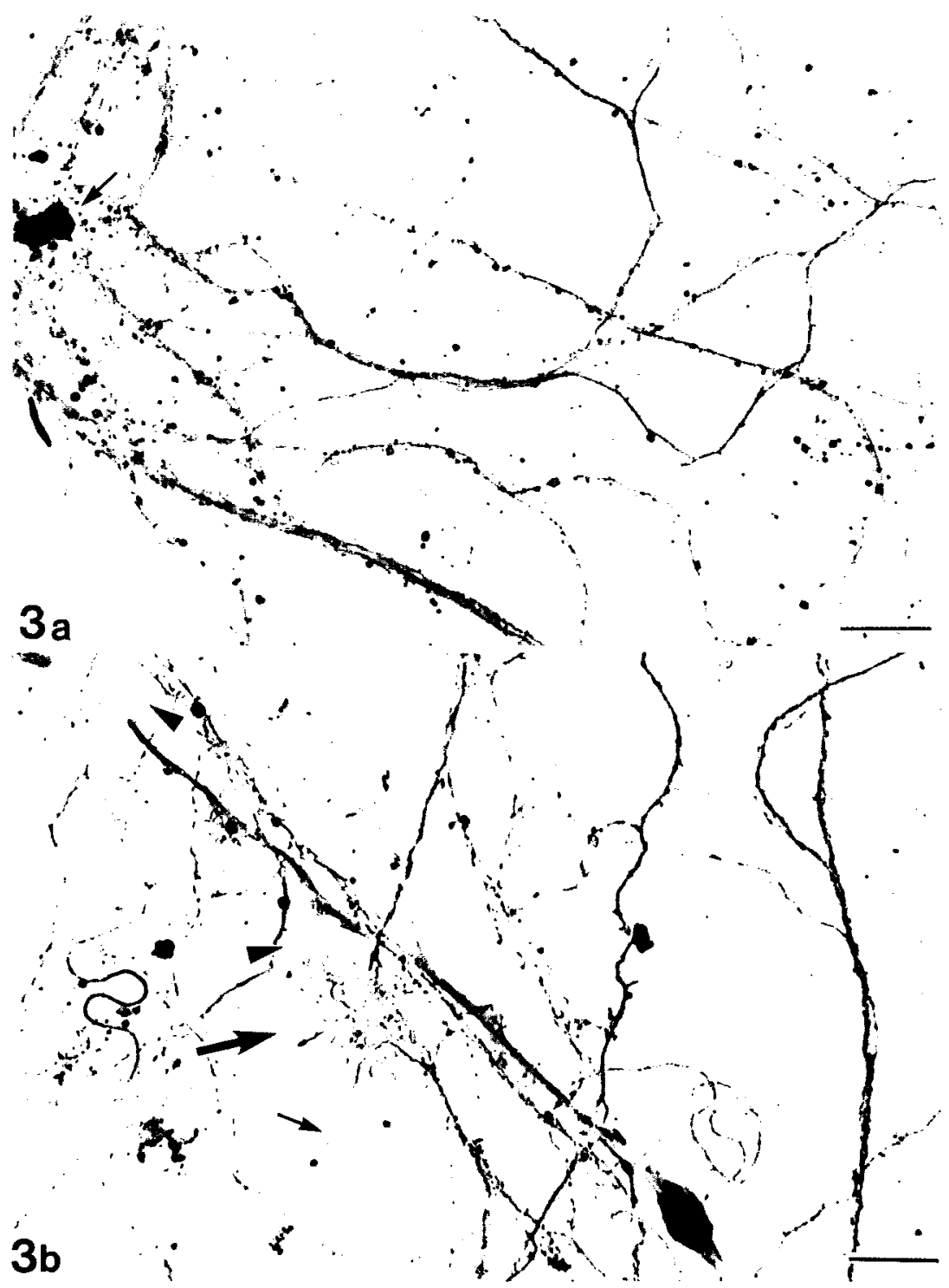

Fig. 3. Immunocytochemical staining for ganglioside $\mathrm{GM}_{1}$ in 21-day-old primary culture growth cones and neurites of rat cortical neurons. Note that growth cones are still present in the culture (arrowhead) and various short filopodia-like structures also are present (3b, large arrow). Many growth cone-like structures remain (arrowhead).

$\mathrm{Bar}=7.6 \mu \mathrm{m} \mathrm{(3a),} \mathrm{Bar}=15 \mu \mathrm{m} \mathrm{(3b)}$ 


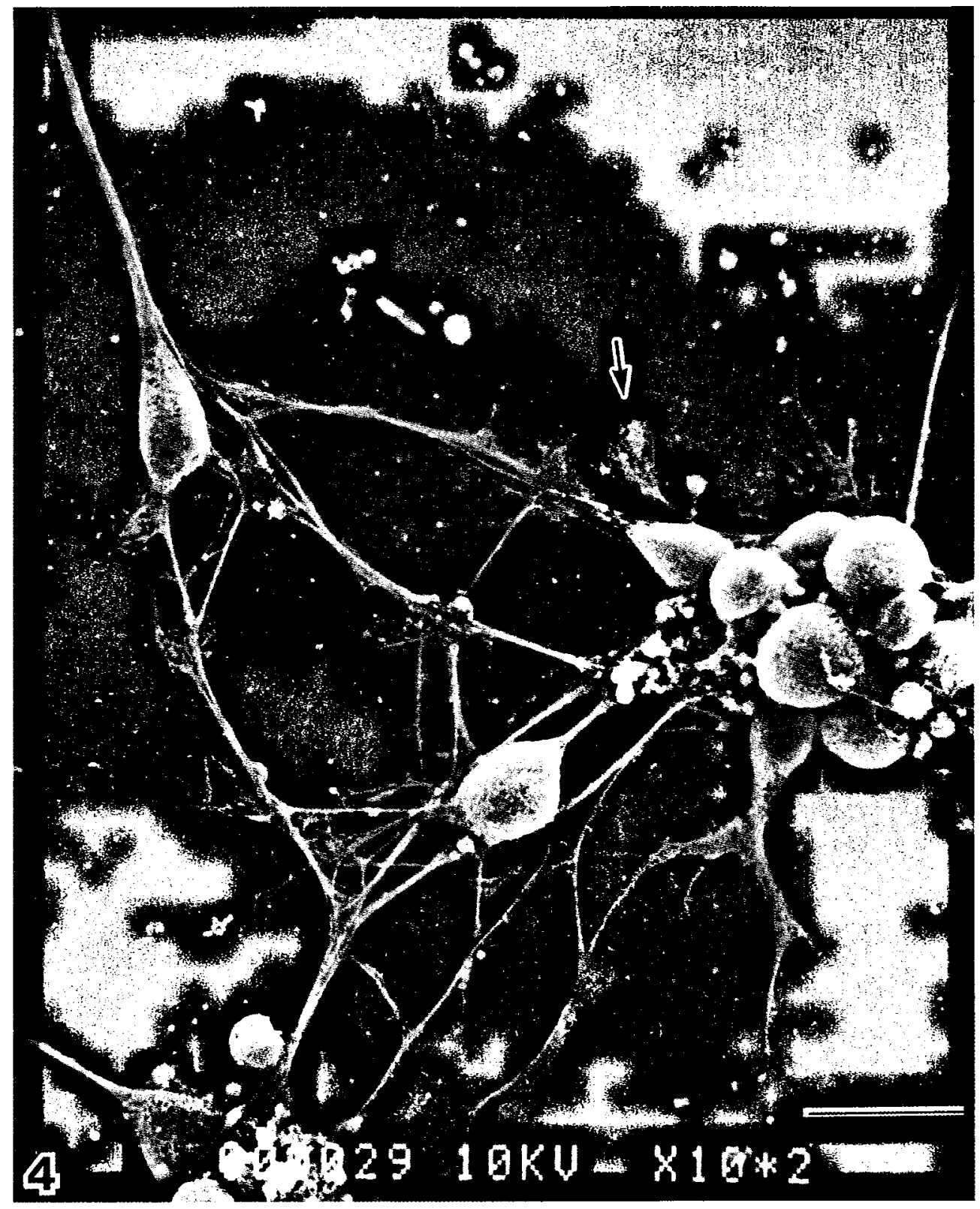

Fig. 4. Scanning electron micrograph of cortical neurons in culture. Growth cones are visible (arrow). Bar $=14.5 \mu \mathrm{m}$ 
The scanning electron microscopic techniques used provided us a convenient means with which to survey the surface of the neurons in order to characterize their morphological features. A growth cone with filopodia (microspike-like) structure is clearly visible in Fig. 4.

\section{DISCUSSION}

Results of numerous morphological studies of growth cones in vivo and in vitro have been reported $(7,9,19,21,24,27)$, but no statistical analysis of the dimensions of the growth cone structure in cultured cerebral cortical neurons has yet been published. We here have identified growth cones that have both filopodia and lamellipodia.

Four types of growth cones also have been characterized by size. About $65 \%$ of the total cones had the dimensions of types 2 and 3 (Table 1). One of the microtips of the filopodia extends to the target neuron (Fig. 2a, b, arrowhead). Our observations suggest that filopodia may interact specifically with particular neurons in their pathway.

Recently, Algiro et al. (1), who used the superior cervical ganglia of the rat, reported that the postnatal nerve growth cones lacked definitive lamellipodia and the filopodia were few. These findings are comparable to our findings with 21-day-old nerve growth cones in an astrocyte-deficient culture. These cones appeared considerably more flattened and had short lamellipodia with branched filopodia (Fig. 3b, large arrow). The veil-like lamellipodia in the long term developing cultures appear to differ from those early in culture. A surprising finding was that one of the tips of the filopodia of the cone that extended to the target neurite still was present in the 21-day-old culture (Fig. 3b, small arrow). Our findings indicate that neurons retain the ability to seek out and extend their processes to target cells for at least 21 days in culture. This ability was retained in the absence of astroglial cells, evidence that these cells have no role in this process.

Little is known about the chemistry of the growth cone membrane $(12,16,22)$ and of how its components are inserted. We have shown that ganglioside $\mathrm{GM}_{1}$ is one such constituent in both 6-day-old and 21-day-old primary cultured cortical neurons. Movement of the growth cone is mediated by various environmental factors present in cultures $(11,13)$, and ganglioside $\mathrm{GM}_{1}$ may function in the establishment of intercellular connections. The culture system we have described appears to be a useful model system with which to study the biochemical, physiological and morphological aspects of the growth cone function.

Acknowledgements. We thank Prof. Eric G. Brunngraber for his editing of the English of our manuscript and Mrs. Y. Sato for her typing of the text.

\section{REFERENCES}

1. Argiro, V., M.B. Bunge and M.I. Johnson. Correlation between growth form and movement and their dependence on neuronal age. J. Neurosci. 4, 3051-3062, 1984

2. Asou, H., N. Iwasaki-Mutou, S. Hirano and D. Dahl. Maintenance of neuritic arborization in mitotic neuroblasts identified by neurofilament immunoreactivity. A scanning electron microscope study of primary cell cultures from embryonic rat cerebral hemispheres. Int. J. Devl. Neurosci. 4, 477-481, 1986 
3. Asou, H., N. Mutou, S. Hirano and D. Dahl. Mitotic neuroblasts in dissociated cell cultures from embryonic rat cerebral hemispheres express neurofilament protein. Brain Res. 332, 355-357, 1985

4. Asou, H., N. Iwasaki-Mutou and S. Hirano. Localization of ganglioside GM $_{1}$ on myelin in dissociated cells from rat embryonic cerebral hemispheres, using biotinylated choleragen and avidin-peroxidase. Neurosci. Res. 2, 399-406, 1985

5. Asou, H., N. Mutou, S. Hirano, T. Tsurumizu and Y. Horibe. Detection of ganglioside $\mathrm{GM}_{1}$ in primary cultured cells of rat brain: avidin-biotin-choleragen and avidin-biotin antibody complex staining methods. Acta Histochem. Cytochem. 18, 383-389, 1985

6. Asou, H., S. Hirano and E.G. Brunngraber. Preparation of astrocyte-deficient cultures containing neurons and oligodendroglia from embryonic rat cerebral hemispheres. Neurosci. Res. 3, 364-370, 1986

7. Bentley, D. and M. CAUdy. Navigational substrates for peripheral pioneer growth cones: limb-axis polarity cues, limb-segment boundaries, and guidepost neurons. Cold Spring Harbor Symposia on Quantitative Biology 48, 573-585, 1983

8. Bray, D. and K. Chapman. Analysis of microspike movements on the neuronal growth cone. J. Neurosci. 5, 3204-3213, 1985

9. Bunge, M.B. Fine structure of nerve fibers and growth cones of isolated sympathetic neurons in culture. J. Cell Biol. 56, 713-735, 1973

10. Cheng, T.P.O. and T.S. REeSE. Polarized compartmentalization of organelles in growth cones from developing optic tectum. J. Cell Biol. 101, 1473-1480, 1985

11. Collins, F. and J.E.Jr. Garrett. Elongating nerve fibers are guided by a pathway of material released from embryonic non neuronal cell. Proc. Natl. Acad. Sci. (USA) 77, 6226-6228, 1980

12. Ellis, L., I. Wallis, E. Abreu and K.H. Pfenninger. Nerve growth cones isolated from fetal rat brain IV, preparation of a membrane subfraction and identification of a membrane glycoprotein expressed on sprouting neurons. J. Cell Biol. 101, 1977-1989, 1985

13. Hammarback, J.A., S.L. Palm, L.T. Furcht and P.C. Letoarneau. Guidance of neurite outgrowth by pathways of substratum-adsorbed laminin. J. Neurosci. Res. 13, 213-220, 1985

14. НАкомовI, S. Glycosphingolipids in cellular interaction, differentiation, and oncogenesis. Ann. Rev. Biochem. 50, 733-764, 1981

15. Haydon, P.G., D.P. McСoвb and S.B. Kater. Serotonin selectively inhibits growth cone motility and synaptogenesis of specific identified neurons. Science 226, 561-564, 1984

16. HART, C.E. and J.G. Wood. A comparative study of the intracellular lectin binding site of neurons in culture with neurons in situ. J. Comp. Neurol. 239, 155-162, 1985

17. LedEen, R.W. Gangliosides, In Handbook of Neurochemistry, A. Lajtha (Ed), Vol. 3 Plenum, New York, pp. 41-90, 1982

18. Letourneau, P.C. Cell-substratum adhesion of neurite growth cones and its role in neurite elongation. Exp. Cell Res. 124, 127-138, 1979

19. Luduena, M.A. and N.K. Wessells. Cell locomotion, nerve elongation and microfilaments. Devel. Biol. 30, 427-440, 1973

20. Marsh, L. and P.C. Letourneau. Growth of neurites without filopodial or lamellipodial activity in the presence of cytochalasin B. J. Cell Biol. 99, 2041-2047, 1984

21. Rees, R., M.B. Bunge and R.P. Bunge. Morphological changes in the neurite growth cone and target neuron during synaptic junction development in culture. J. Cell Biol. 68, 240-263, 1976

22. Schlosshauer, B. Membrane proteins and glycoprotein specific to central nervous system axons and growth cones. Dev. Brain Res. 19, 237-244, 1985

23. Sternberger, L.A. The unlabelled antibody peroxidase-antiperoxidase (PAP) method. In Immunocytochemistry, L.A. Sternberger (Ed) 2nd Ed., John Wiley and Sons, New York, pp. 104-169, 1979

24. Tennyson, V.M. The fine structure of the axon and growth cone of the dorsal root neuroblast of the rabbit embryo. J. Cell Biol. 44, 62-79, 1970

25. ToSney, K.W. and L.T. LANDMESSER. Specificity of early motoneuron growth cone outgrowth 
in the chick embryo. J. Neurosci. 5, 2336-2344, 1985

26. TosNey, K.W. and L.T. LANDMesSer. Growth cone morphology and trajectory in the lumbosacral region of the chick embryo. J. Neurosci. 5, 2345-2358, 1985

27. Yamada, K.M., B.S. SPOONER and N.K. Wessells. Ultrastructure and function of growth cones and axons of cultured nerve cells. J. Cell Biol. 49, 614-635, 1971

(Received for publication, October 28, 1986) 